\title{
Biodegradation of Azo Dyes Using Bacillus Megaterium and Its Phytotoxicity Study
}

\author{
*Lekha K.Nair r ${ }^{1}$, Dr.Maleeka Begum² ${ }^{2}$, Dr.R.Ragunathan ${ }^{3}$ \\ ${ }^{I}$ Research Scholar Dept. of Biotechnology, Bharathiar University, India) \\ ${ }_{2}^{2}$ (Head Dept. of Biotechnology, Sri Krishna Arts and Science College, India) \\ ${ }^{3}$ (Director, Centre for Bioscience and Nanoscience Research, India)
}

\begin{abstract}
The release of azo dyes from various textile industries contributes a serious problem to the environment. The biological method of degrading these dyes is preferred over chemical and physical methods. In the present study, the potentiality of using Bacillus megaterium (MTCC 8371) for degrading four different azo dyes, namely methylene blue, methyl red, congo red, and orange $-G$, under optimum conditions were studied. Kirk's media was used for the degradation study and it was found out that the organism degraded the dye best in Kirk's media on the fifth day of incubation under neutral $\mathrm{pH}$ at 40oC. The degradation was estimated by using UV-VIS spectrophotometer. FTIR study was also carried out to find out the degraded compounds in the samples. TLC was performed to find out the $R f$ value of the degraded dyes. The molecular weight of laccase enzyme was identified by SDS-PAGE and the degradation was further conformed by laccase assay. GC-MS analysis was also performed for the further confirmation of degradation.
\end{abstract}

Keywords : degradation, Kirk'smedium, Rf value, Methylene blue, Orange G, Congo Red, Methyl Red.

\section{Introduction}

The increasing globalization, urbanization, and industrialization have caused different environmental pollution. Among various industries, the textile dying industries discharge large volume of waste water after dyeing process [1]. Dyes usually have a synthetic origin and complex aromatic molecular structures which make them more stable and more difficult to biodegrade. Most commonly azo dyes which produce clear and strong colors are used in the textile industries. Generally, synthetic dyes are used in paper industry, textile, cosmetics, food and pharmaceutical industries. Some azo dyes are carcinogenic and mutagenic [2]. They reduce the efficiency of seed germination and plant growth. Untreated effluents with higher concentration of dyes inhibit the elongation of shoot and roots [3].Malachite green causes serious public health hazards and environmental problem.

Currently, several methods including physiochemical and biological removal of dyes from effluents, waste water and soil are extensively studied. Among these, biotechnological approaches are receiving increased attention worldwide as environmental-friendly methods that are becoming increasingly efficient and costeffective for the remediation of dye-contaminated wastewater [4]. Many bio treatment systems rely on the use of sludge as an inoculum to initiate the dye degradation process [5]. While generally effective, it is nonetheless important to assure complete mineralization and detoxification for use as a reliable treatment method.

In recent years several microorganisms have been investigated in the decolourization of the azo dyes [6]. Azo dyes and their degraded intermediates vary in their recalcitrance to biodegradation due to their complex structures and xenobiotic nature. Furthermore, azo-dye degrading microbial communities are sensitive to high concentrations of salts that are used in the dye process [7]. This can limit growth and activity of the degrader bacteria such that the process treatment times become impractical.

Hence, there is a need for the discovery and isolation of very efficient, salt-tolerant azo dye degrading bacteria. Bioaugmentation of biotreatment systems with specific microbial strains has now become an effective strategy to improve wastewater treatment systems and to enhance the bioremediation of azo dyes. Although many microorganisms can degrade azo dyes, relatively few microbial species and strains have emerged as candidates for use in bioaugmentation[8].

Bacillus megaterium is used as an industrial organism for more than 50 years because of its wide availability, growth even in simple media and production of effective proteins. In the present study four azo dyes ( Methylene blue, Methyl red, Orange $\mathrm{G}$ and Congo red $500 \mathrm{mg} / \mathrm{L}$ ) are degraded using B. megatarium ( MTCC 8371) under optimized condition and the \% of degradation were carried out by UV -Visible, FTIR, SDS PAGE and GC- MS analysis study. 


\section{Materials And Methods \\ 2.1 Microorganism and Culture media \\ The Bacillus megaterium (MTCC 8371) were obtained from MTCC, Chandigarh, India. The sample inoculated in nutrient agar slant and incubated at $37^{\circ} \mathrm{C}$ for 24 hours and then stored at $4{ }^{\circ} \mathrm{C}$ and periodically sub- cultured for further study. The media for the growth of the bacteria and the decolorization study was carried out with Kirk's medium (D-glucose 10g, KH2PO4 $2 \mathrm{gm}, \mathrm{MgSO} 4.7 \mathrm{H} 2 \mathrm{SO} 40.5 \mathrm{gm}, \mathrm{CaCl} 2.2 \mathrm{H} 2 \mathrm{O} 0.1 \mathrm{gm}, \mathrm{L}-$ Asparagine monohydrate $93 \mathrm{mg}$, NH4NO3 50mg, 6M KOH, Nitrogen supplements, Trace element solution $1 \mathrm{ml}$, thiamine $100 \mu \mathrm{g}$, dialyzed poly acrylic acid $0.72 \mathrm{gm} / \mathrm{L}$ of glass distilled water). All microbiological media and medium ingredients were purchased from HiMedia Laboratories (Mumbai, MH, India).}

\subsection{Azo Dyes}

Methylene blue, Methyl red, Orange G and Congo red dyes also obtained from Hi Media, Mumbai were used for the study. All chemicals and dyes were of highest purity and were of analytical grade.

\subsection{Optimization of Carbon and Nitrogen source}

Decolourisation effect of the B.megaterium was tested using three different carbon sources and nitrogen sources. The Kirk's media (Selvam and Swaminathan 2003) is optimized with carbon sources (Glucose, Sucrose and maltose) and nitrogen sources (K2HPO4, KH2PO4, and Peptone) for attaining high decolorisation effect.

\subsection{Degradation Analysis}

The bacterial culture was inoculated into Kirk's Medium (pH 6.0) in the 100ml Erlenmeyer flask. The flasks were then incubated at room temperature in orbital incubator- $150 \mathrm{rpm}$ for 8 days. $5 \mathrm{ml}$ of the dyes of concentration $500 \mathrm{mg} / \mathrm{L}$ and $1000 \mathrm{mg} / \mathrm{L}$ were added to the culture on the second day. Simultaneously, controls were also maintained in the same conditions without the addition of inoculums at neutral $\mathrm{pH}$. The biomass, decoloration and $\mathrm{pH}$ were observed every $6 \mathrm{~h}$.

\subsection{U-V visible Nano Drop Spectrophotometer}

The biomass and decoloration were calculated by measuring the OD at specific nm: Methyl Red: $(560 \mathrm{~nm})$; Malachitegreen: $(617 \mathrm{~nm})$; Methyl orange: $(487 \mathrm{~nm})$; Congo red (Merck) $(580 \mathrm{~nm})$ and Methylene blue $(660 \mathrm{~nm})$. The degradation study was monitored by measuring the absorbance as a UV-Vis spectrum of reaction medium by drawing $1 \mathrm{~cm} 3$ medium on UV visible ELICO SL 159 nanodrop spectrophotometer. The percentage decolourization was calculated from the following equation,

$\%$ Decolourization= $($ Initial OD-Final OD *100)/Initial OD

\subsection{Fourier Transform Infrared (FTIR) Spectroscopy analysis}

The sample was subjected to FTIR Spectroscopy analysis (Shimazdu). Two milligrams of the sample was mixed with $200 \mathrm{mg} \mathrm{KBr}$ (FT-IR grade) and pressed into a pellet. The sample pellet was placed into the sample holder and FT-IR spectra were recorded in the range 4000-450 cm-1 in FT-IR spectroscopy at a resolution of $4 \mathrm{~cm}-1$.

\subsection{TLC Analysis of biodegradable product}

The degraded product was extracted from the strain. Cells were centrifuged and supernatant was extracted with the equal volume of ethyl acetate and then dried over anhydrous sodium sulphate. The residue was dissolved in a small amount of methanol and this was utilized for a TLC test. The developing solvent systems used were ethylacetate: hexane $(2: 3 \mathrm{v} / \mathrm{v})$ for biotransformed intermediates/products and ethyl acetate: methanol $(7: 3, \mathrm{v} / \mathrm{v})$ for residual dye. The bands of aromatic compounds were observed under UV light $(365 \mathrm{~nm})$.

\subsection{Enzyme assay}

The laccase activity was determined by measuring the oxidation of 2, 2'-azino-bis 3ethylbenzothiazoline-6-sulphoric acid (ABTS) (Sigma). Increase in absorbance in 3 minutes was measured spectrophotometrically at $420 \mathrm{~nm}(\varepsilon=36000 \mathrm{~cm} 1 \mathrm{M1})$ [9] Niku-Paavola et al., 1990). The reacting mixture contained $200 \mu \mathrm{l}$ of $50 \mathrm{mM}$ ABTS and $1000 \mu$ lof $20 \mathrm{mM} \mathrm{Na}$-acetate buffer (pH4.6) and $500 \mu \mathrm{l}$ of approximately enzyme extract Supernatant). One unit of enzyme activity is defined as the amount of enzyme that oxidized $1 \mu \mathrm{M}$ of substrate per min.

\subsection{Purification and characterization of azoreductase enzyme}

Cells from the mid log phase culture were harvested by centrifugation at $10,000 \mathrm{rpm}$ for 10 minutes at $4{ }^{\circ} \mathrm{C}$. Pellets were disrupted by sonication at $40 \%$ power for 6 minutes. The cell lysate was subjected to fractionated 
ammonium sulfate precipitation at $40 \%$ saturation to remove impurities, followed by $70 \%$ saturation in a second step to precipitate the azoreductase. After $24 \mathrm{hrs}$, the precipitated protein is centrifuged for 10 minutes at 10000 $\mathrm{rpm}$ at $4^{\circ} \mathrm{C}$ and the pellet was dissolved in equal volume of $50 \mathrm{mM}$ potassium phosphate buffer ( $\left.\mathrm{pH} 7.2\right)$. Ammonium sulfate precipitated sample was then desalted by dialysis against phosphate buffer $(50 \mathrm{mM}, \mathrm{pH} 7)$ overnight under room temperature. $2 \mathrm{~mL}$ of the resulting solution was fractionated by anion exchange chromatography using DEAE sephadex column. Elution buffer (sodium phosphate buffer containing $1 \mathrm{M} \mathrm{NaCl}$ was set to a gradient of $100 \%$ for 150 minutes. Proteins were eluted at a flow rate of $1 \mathrm{~mL} / \mathrm{minute}$. The fractionated sample was concentrated using protein purification column. Active fractions were collected and stored as the purified enzyme preparation.

\subsection{Assay of Azoreductase activity}

Assays were carried out in cuvettes with a total volume of $1 \mathrm{~mL}$ using ELICO SL159 UV- VIS Nanodrop Spectrophotometer. The reaction mixture consists of $400 \mu \mathrm{l}$ of potassium phosphate buffer $(50 \mathrm{mM})$ with $200 \mu \mathrm{l}$ of sample and $200 \mu \mathrm{l}$ of reactive dyes $(500 \mathrm{mg} / \mathrm{l})$. The reaction was started by addition of $200 \mu \mathrm{l}$ of $2 \mathrm{mM}$ NADH $(7 \mathrm{mg} / \mathrm{mL})$ and was monitored photometrically at $532 \mathrm{~nm}$. The linear decrease of absorption was used to calculate the azoreductase activity. One unit of azoreductase can be defined as the amount of enzyme required to decolorize $1 \mu \mathrm{mol}$ of acid red per minute. The assay procedure is based on the principle that with the addition of NADH to the reaction mixture containing substrate, buffer and enzyme solution, the substrate azodyes azo bond is degraded and there is a decrease in the absorbance of the dye after an initial lag phase. One unit will reduce $1.0 \mu$ mole of azo dye per minute in the presence of NADH using Millimolar extinction coefficient of azo dye at $\mathrm{pH} 7.0$ and $30^{\circ} \mathrm{C}$ temperature:

Units $/ \mathrm{ml}$ enzyme $=\quad$ A $532 \mathrm{~nm} / \min$ Test $-\mathrm{A} 532 \mathrm{~nm} / \min$ blank $(2)$

B X $(0.1)$

$\mathrm{A}=$ Total volume (in milliliters) of assay; $\mathrm{B}=$ Millimolar extinction coefficient of azo dye, Methyl red (1.5x105); 0.1 = Volume (in milliliter) of enzyme used.

\subsection{Molecular Characterization}

\subsubsection{Plasmid isolation and SDS- PAGE}

The plasmid of the bacteria was isolated using manual method of Plasmid isolation by mini prep method and checked in the $1.0 \%$ Agarose Gel Electrophoresis. The SDS-PAGE was carried out to ascertain the presence of the Azoreductase enzyme. The sample was prepared for analysis by adding sample buffer ( $\beta$ mercaptoethanol and bromophenol blue) added in ratio 1:5 and the mixture was heated at $100^{\circ} \mathrm{C}$ for 2 min and then spun down for few seconds and then loaded in the wells of $12.5 \%$ acrylamide polymerized gel in gel apparatus. Marker also loaded in separate well to determine the molecular weight of the samples. The power supply was given is $100 \mathrm{~V}$ without any disturbances. After running this were further kept for staining and distaining process to visualize the enzyme bands.

\subsection{Phytotoxicity study}

Phytotoxicity is a toxic effect which affects the compounds and growth of the plants. Phytotoxicity study were done to identify the problems and nutrient level changes of the plants. In this study, green gram (Vigna radiata) plant were selected and three type treatment given to the plants i.e.; with tap water as control; dye treatment (methylene blue, methyl red, Congo red, and orange G) and with B.megaterium treated dye waste water as a sample. The above mentioned were used as water sources for the plants and studied for two weeks. The changes were noticeable and recorded. The root and shoot length, height of the plants number of leafs were studied. Apart from this, nutrient analysis protein [10] and carbohydrate [11] also done which also shown better results for treated dyes.The toxicity studies on the sample dyes (untreated) and the extracted metabolites (treated) obtained after the biodegradation of the selected azo dyes by B.megatarium on the plants was carried out in two concentrations $500 \mathrm{mg} / \mathrm{l}$ and $1000 \mathrm{mg} / \mathrm{l}$.

\section{Figures and TABLES}

Colored textiles have always fascinated mankind. Textiles are colored by the use of dyes during the process of dyeing and printing. Textile dying and printing is among the oldest industrial sectors. There are various physiochemical methods available for the removal of dyes from waste water but a number of drawbacks are associated with each of them, therefore, there is a need for a method which is efficient and also meets the environmental regulatory requirements. The use of microorganisms has been emphasized from past few years 
for the removal of toxic azo dyes. Therefore an attempt has been made in the present study to verify the biodecolorization and biodegradation of these textile azo dyes using B. megaterium.

Kirks medium [12] Selvam and Swaminathan (2003) were used for the degradation study, after preparation of the medium $5 \mathrm{ml}$ of Congo red, methyl red, methylene blue and orange $\mathrm{G}$ were added in different concentration of 500 and $1000 \mathrm{mg}$ separately. And this were incubated for 24 hours and added the culture B. megaterium and again incubated and the growth of organism and decolorisation were studied using different parameters. Estimation of biomass is the primary step to identify the growth of the bacteria and this were visually identified by the color change of the different dyes and absorbance, which is showing in Fig. $1 \& 2$.

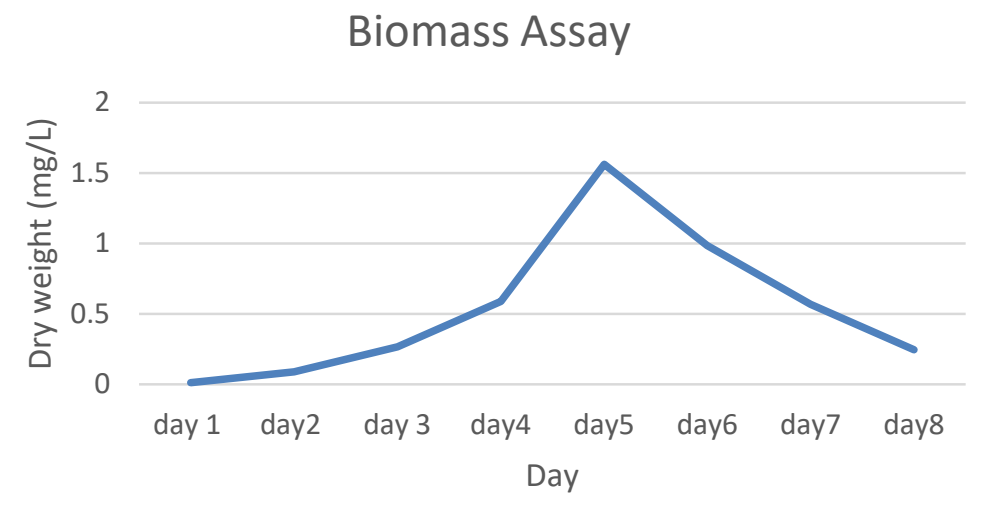

Bacillus megaterium

Figure 1. Estimation of biomass for the $500 \mathrm{mg} / \mathrm{ml}$ dye

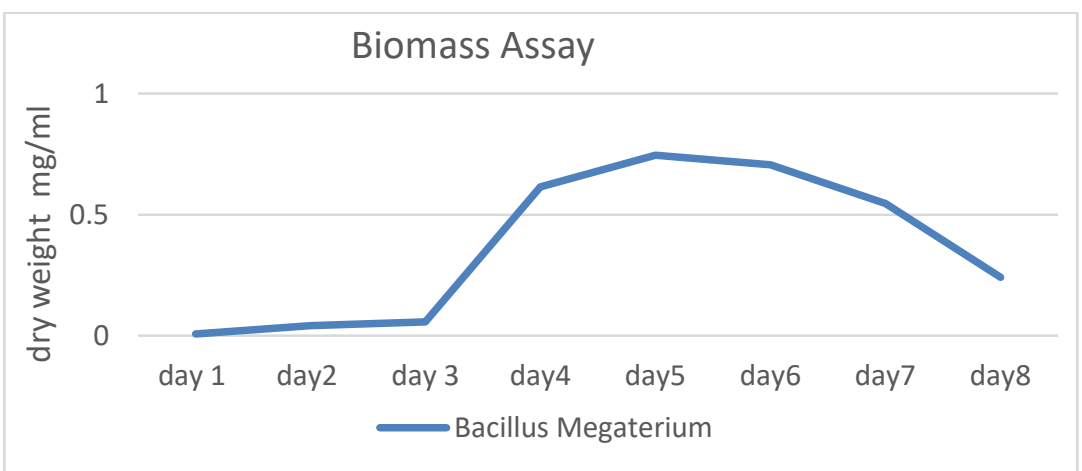

Figure 2. Estimation of biomass for the $1000 \mathrm{mg} / \mathrm{ml}$ dye

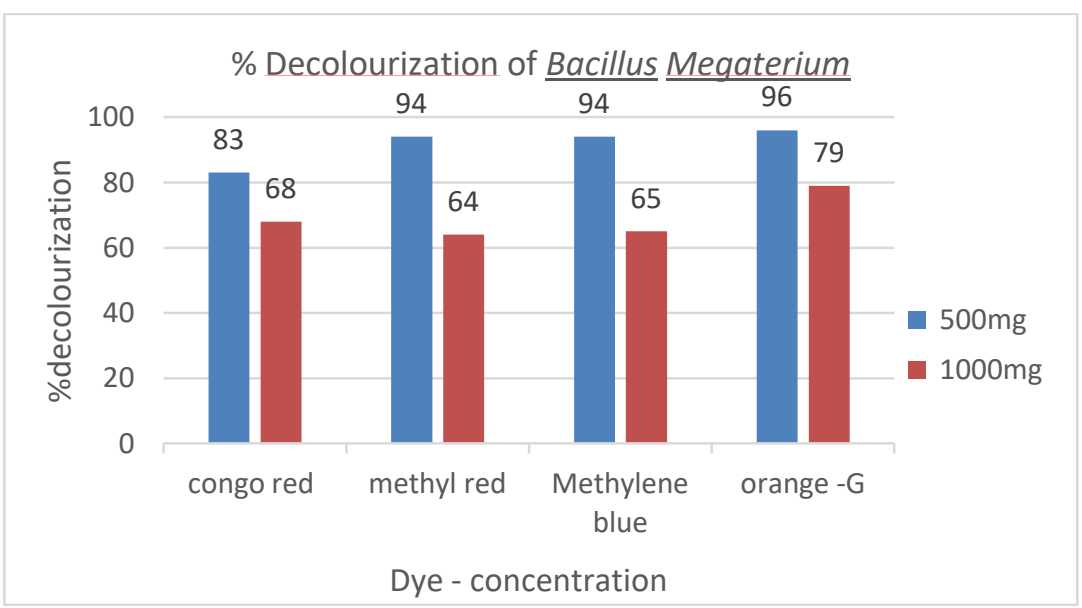

Figure 3. Percentage of decolourisation in different dyes

Dye decolourisation assay was measured in terms of percentage decolourization using UV Spectrophotometer. In this study orange G shows good results in both 500 and $1000 \mathrm{mg} \mathrm{L}$ concentration, methyl 
red and methylene blue is showing equal percentage of decolorisation and Congo red is taking more time to decolor.

\subsection{Optimization of carbon and nitrogen source}

The effect of conventional sources of an adaptation of bacteria for the production of enzyme includes study of their carbon and nitrogen sources. Different type carbon sources are used that are glucose, sucrose and maltose. Each carbon sources were added separately in equal concentration and were observed. The bacterial strain showed high decolourization capacity with glucose as carbon source for all dyes except Orange-G after 8 days of incubation. Three different type of nitrogen sources K2HPO4, KH2PO4, and peptone are used to differentiate the activity of the sample in which K2HPO4 is showing the best result.

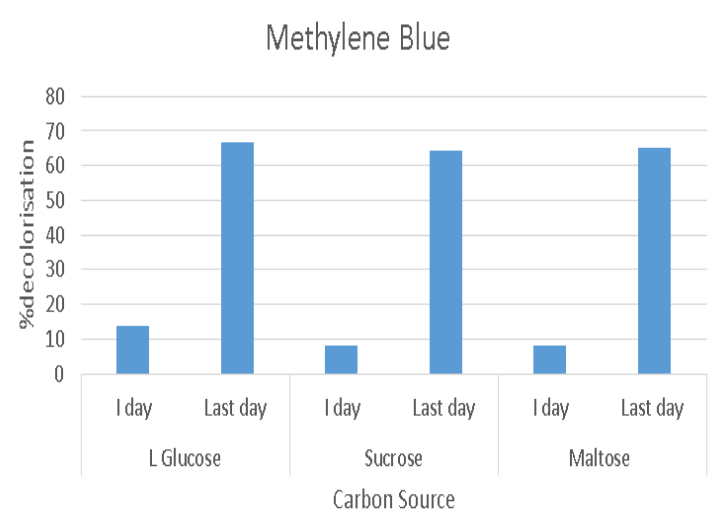

B. megaterium

Congo Red

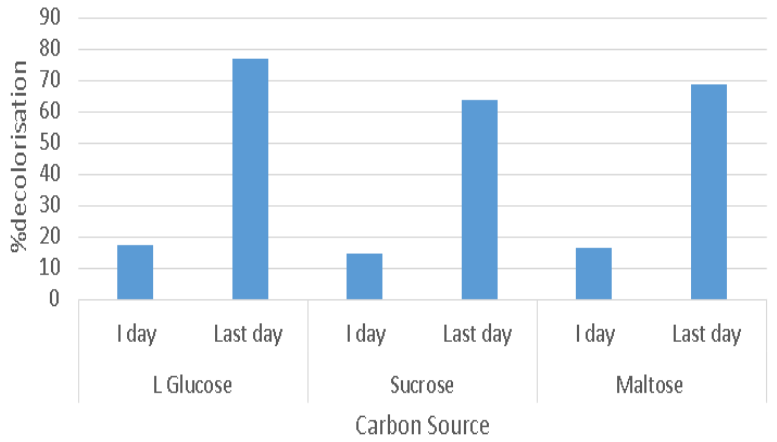

¿ B. megaterium

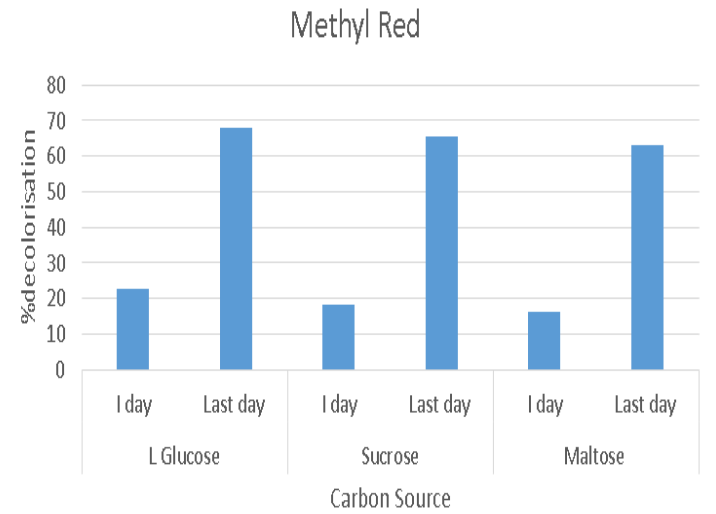

B. megaterium

\section{Orange $-G$}

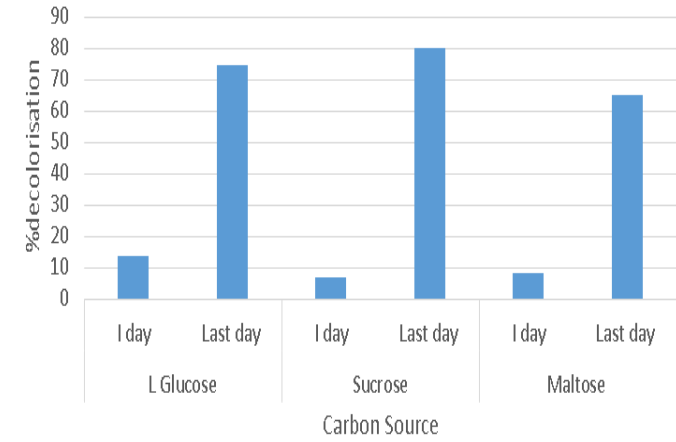

B. megaterium

Figure 3. Carbon and nitrogen source

Since the dyes are deficient in carbon source, it seems necessary to supplement additional carbon or nitrogen source to assist biodegradation of dyes by the bacterial consortium. [13] Showed negligible decolorization in the presence of sucrose $(25 \%)$ whereas moderate activity was shown in presence of glucose (55\%), lactose (80\%) and maximum decolorization was reported in presence of starch (95\%). In addition, supplying urea as a nitrogen source exhibited less decolorizing ability. Similar results were reported by Saratale. In contrast, addition of carbon sources seemed to be less effective to promote the decolorization probably due to the preference of the cells in assimilating the added carbon sources over using the dye compound as the carbon source.

\subsection{FTIR}

Formation of nitrosamines, alkyl chloride, secondary and tertiary amides after decolorization. The chemical structure of the dye greatly influenced their decolorization rates and the decolorization efficiency is limited to several azo dye structures. Here the FTIR study were done to identify the dye compounds are 
degraded or not, without treatment and treated dye were studied, from the results compared to control dye the treated dye were shown different peak value for both congored and methyl red sample.
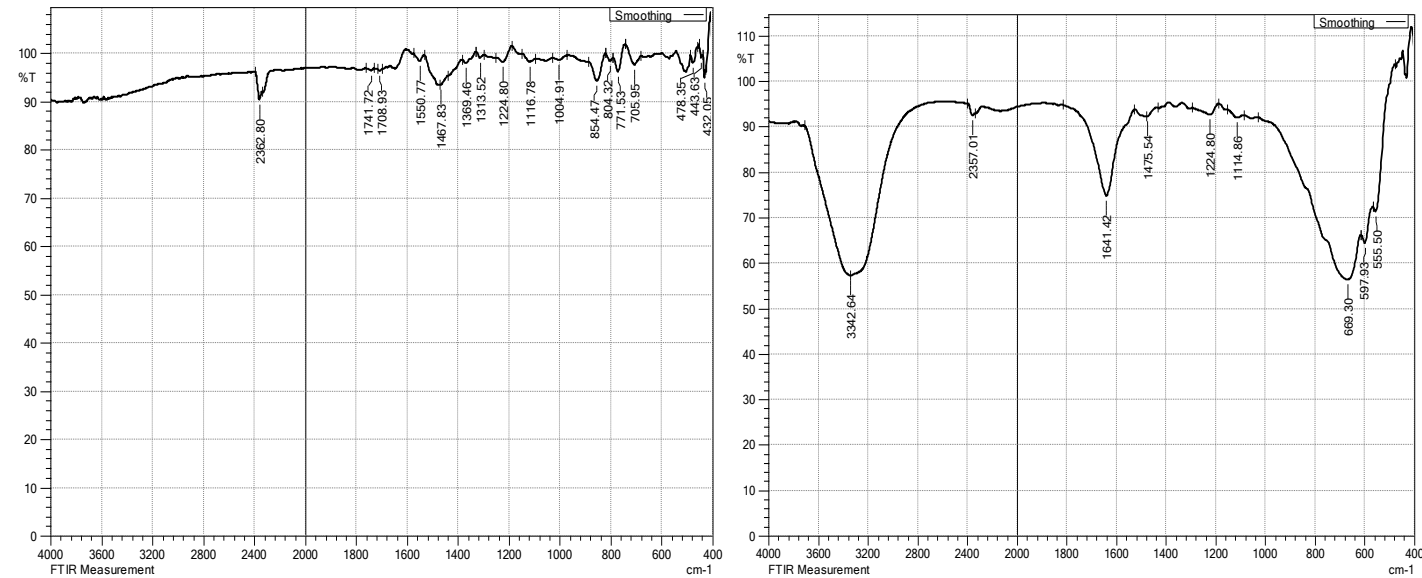

Figure 4. FTIR Results for congo red control and treated
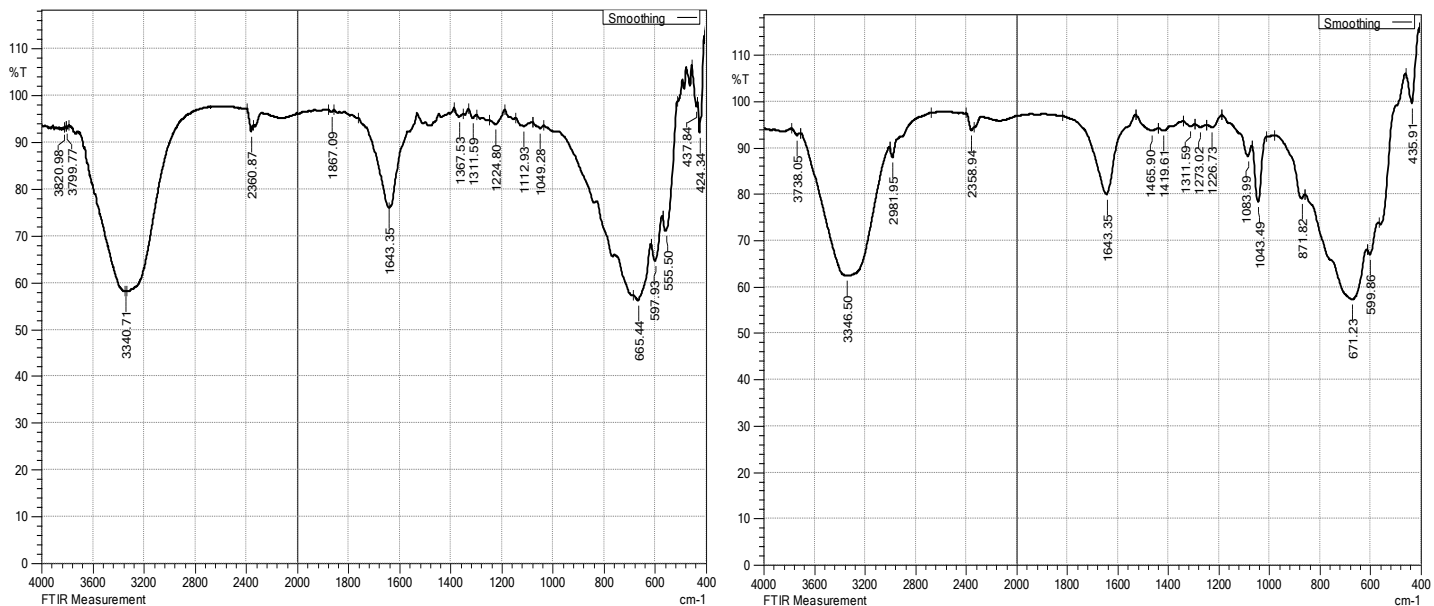

Figure 4. FTIR Results for methyl red control and treated

FTIR [14] spectra obtained from control dye Rubine GFL showed specific peaks at 779.766e910.90 cm_1 and $1173.17 \mathrm{~cm} \_1$ for $\mathrm{CeH}$ deformation, $1202.15 \mathrm{~cm} \_1$ for $\mathrm{CeN}$ vibrations, $1341.18 \mathrm{~cm} \_1$ for NO2 stretching of aromatic nitro compound, $1520.82 \mathrm{~cm} \_1$ for N] O stretching of aromatic nitro compound, 1599.45 cm_1 for $\mathrm{N}] \mathrm{N}$ stretching in azo group, $2248.70 \mathrm{~cm} \_1$ for $\mathrm{C}^{\wedge} \mathrm{N}$ stretching in saturated nitriles and $2926.58 \mathrm{~cm} \_1$ for $\mathrm{CeH}$ stretching in alkanes. After the consortium decolorization, a significant reduction in IR peaks was observed in the $2845.20 \mathrm{~cm} \_1$ to $2322.06 \mathrm{~cm} \_1$ regions of metabolites suggests absence of charged amines in theproduced metabolites. A significant peak at $1659.73 \mathrm{~cm} \_1$ for NHp 3 deformation suggest the possible alkenes conjugation with CO. Moreover, peaks at $992.89 \mathrm{~cm} \_1$ and $1151.77 \mathrm{~cm} \_1$ for CeH deformation suggests cleavage of dye molecule. The absence of peak at $1599.75 \mathrm{~cm} \_1$ for $\left.\mathrm{N}\right] \mathrm{N}$ stretching vibrations indicates the reductive cleavage of azo bond Vanishing of major peaks and formation of new peaks in the IR spectrum of consortium-AP metabolites suggests the biotransformation of dye into distinct metabolites Enhanced biodegradation and detoxification of disperse azo dye Rubine GFL and textile industry effluent by defined fungal-bacterial consortium.

\subsection{TLC study}

The TLC analysis of dye degraded products shows Rf value of the dye sample is for methylene blue 0.90 after treatment for $500 \mathrm{mg}$ the value is 0.64 and for 1000 it is 0.65 for methylred before treatment 0.83 after treatment for $500 \mathrm{mg} 0.51$ and for $1000 \mathrm{mg} 0.67$, congo red before treatment 0.88 and after treatment it is decreased to 0.45 and for $1000 \mathrm{mg}$ it is 0.54 , orange $\mathrm{G}$ also shows positive results that is when it is without treatment the Rf value is 0.78 and after treatment for $500-0.42$ and for $1000 \mathrm{mg}$ it is 0.54 , which means that the compound or the dye degradation has happened. 


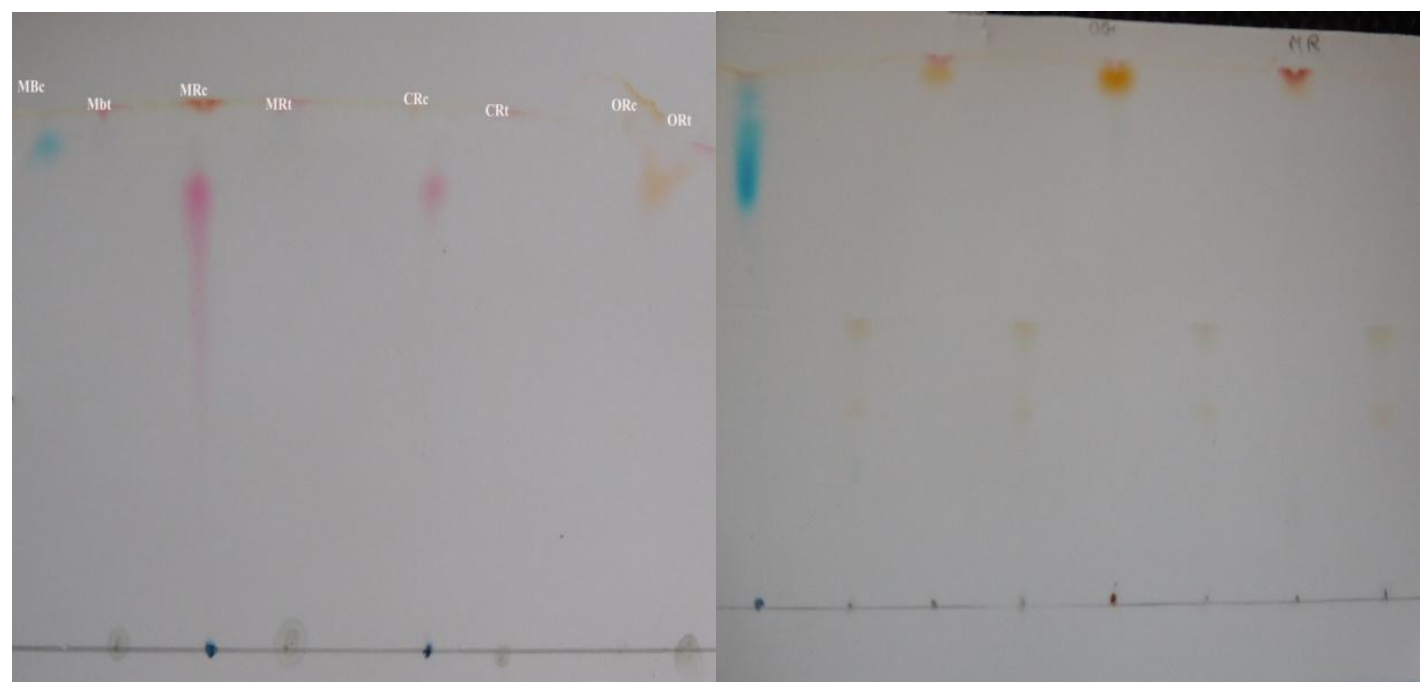

Figure 5. TLC plate for 500mg and $1000 \mathrm{mg}$

Table1: Result (Rf value)

\begin{tabular}{|l|c|c|c|}
\hline \multirow{2}{*}{ Dye } & \multirow{2}{*}{ Control } & \multicolumn{2}{|c|}{ Concentration $(\mathrm{mg} / \mathrm{L})$} \\
\cline { 3 - 4 } & & \multicolumn{2}{|c|}{ Rf value } \\
\cline { 3 - 4 } & & 0.64 & 0.65 \\
\hline Methylene Blue & 0.90 & 0.51 & 0.67 \\
\hline Methyl Red & 0.83 & 0.450 & 0.51 \\
\hline Congo Red & 0.88 & 0.42 & 0.54 \\
\hline Orange $-\mathrm{G}$ & 0.78 & \multicolumn{2}{|l}{} \\
\hline
\end{tabular}

[15] Reported that the dye decolorization study of bacterial isolate was supported by TLC analysis. When the dye chromatogram was observed in UV light, the brown spot with Rf value $0.22,0.35,0.35,0.26$ and 0.35 were observed while no such band were observed for spots of dye and Uninoculated medium, strongly indicating that decolorization was only due to dye degradation.

Table2: Enzyme assay

\begin{tabular}{|c|c|c|}
\hline \multirow{3}{*}{ Dye } & \multicolumn{2}{|l|}{ Concentration (mg.L) } \\
\hline & 500 & 1000 \\
\hline & \multicolumn{2}{|l|}{ Enzyme activity $(\mathrm{u} / \mathrm{mL})$} \\
\hline Methylene Blue & 45.23 & 21.41 \\
\hline Methyl Red & 56.87 & 34.04 \\
\hline Congo Red & 84.12 & 62.10 \\
\hline Orange - G & 94.23 & 52.14 \\
\hline
\end{tabular}

\subsection{SDS PAGE and Plasmid isolation}

The molecular weight of purified azoreductase was determined by gel electrophoresis using standard marker. The partially purified azo reductase revealed band on 10\% SDS-PAGE with an estimated molecular weight of $60 \mathrm{KDa}$ approximately [16] investigated the degradation of azo dye using Enterococcus faecium and in SDS study they got $23 \mathrm{KDa}$ molecular weight after degradation study.

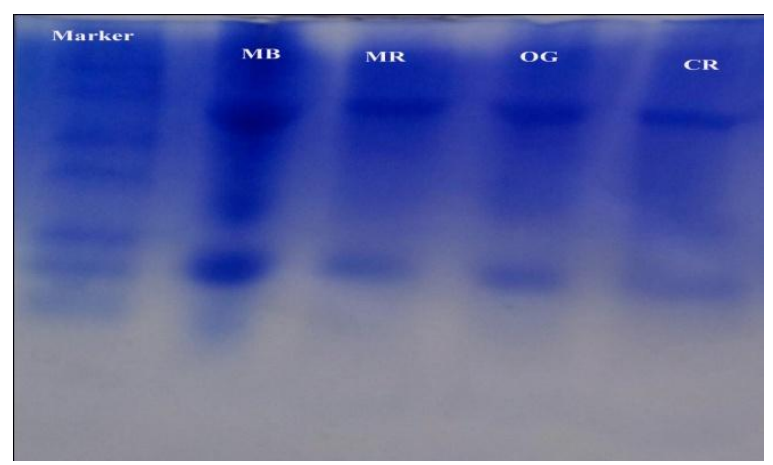

Figure 6. SDS PAGE 
To determine the plasmid harboring the catabolic genes involved in azo dye degradation, electrophoretic profiles of plasmids isolated from various treated dyes were used, Bacillus megaterium shown different molecular weight for different type of dye.

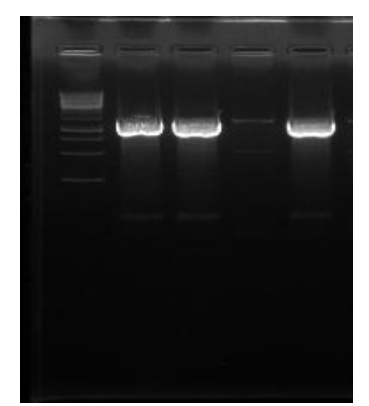

Figure 7. The presence of plasmids confirmed the plasmid mediated degradation.

\subsection{Phyotoxicity}

The plants were treated with tap water, dye contaminated water and B.megaterium treated dye water. In all these parameters treated dye and tap water poured plants (Green gram) shown better results compared to untreated dyes. Apart from this nutrient analysis also done which also shown better results for treated dyes. Shoot and root lengths are equal in control (tap water and treated dye water samples), whereas in the dye treated samples the shoot and root lengths are less when compared with the control.

Table 3: Shoot and root length

\begin{tabular}{|l|c|c|c|c|c|c|}
\hline \multirow{4}{*}{ Dye } & \multicolumn{9}{|c|}{ Length (in cm) } \\
\cline { 2 - 7 } & Control (Tap Water) & \multicolumn{2}{c|}{ Dye } & \multicolumn{2}{c|}{ Treated } \\
\cline { 2 - 7 } & Shoot & Root & Shoot & Root & Shoot & Root \\
\hline MB & 7.12 & 2.89 & 5.63 & 2.3 & 5.9 & 3.9 \\
\hline MR & 6.2 & 4.2 & 3.8 & 1.9 & 6.4 & 3.2 \\
\hline CR & 6.0 & 3.8 & 2.9 & 2.3 & 6.8 & 3.8 \\
\hline OG & 6.8 & 3.8 & 3.4 & 1.2 & \multicolumn{2}{c}{} \\
\hline
\end{tabular}

\subsection{Estimation of carbohydrate (Anthrone method) and Protein (Lowrys Method)}

The plants grown in tap water were taken as control. They were compared with the dye contaminated water grown plants and dye treated water grown plants. Estimation of carbohydrate and proteins were done by anthrone methods and Lowry's method respectively, Spectrophotometric methods were utilised and the OD were taken at $620 \mathrm{~nm}$ and $660 \mathrm{~nm}$ respectively for the Anthrone and Lowry's et al (1951) method as BSA as standard. The amount of carbohydrates and proteins of the plant extracts were tested for all the plants. It was noted that the plants grown using treated water contained almost the same concentration of carbohydrates and proteins as the control. Hence, it can be inferred that the decolorisation has been proved effective since they did not affect the carbohydrate and protein concentration of the plant. Glucose was used as a standard for the anthrone method and were prepared by mixing $10 \mathrm{mg} / 100 \mathrm{ml}$ concentration.

Table 4: Estimation of carbohydrate

\begin{tabular}{|l|c|c|c|}
\hline Dye & \multicolumn{3}{|c|}{ Amount of carbohydrate (mg/g) } \\
\hline & Control(Tap Water) & Dye & Treated \\
\hline MB & 256 & 132 & 234 \\
\hline MR & 237 & 106 & 229 \\
\hline CR & 246 & 157 & 240 \\
\hline OG & 252 & 186 & 251 \\
\hline
\end{tabular}

Table 5: Estimation of protein

\begin{tabular}{|l|c|c|c|}
\hline Dye & \multicolumn{3}{|c|}{ Amount of protein $(\mathbf{m g} / \mathbf{g})$} \\
\hline & Control(Tap Water) & Dye & Treated \\
\hline MB & 86 & 42 & 72 \\
\hline MR & 79 & 56 & 76 \\
\hline CR & 89 & 70 & 82 \\
\hline OG & 104 & 94 & 102 \\
\hline
\end{tabular}




\section{Conclusion}

A Microbial degradation is one of the best techniques to detoxify and decolour the azo dyes. The present study involves the successful study of the potency of B.megaterium to decolorize and degrade azo dyes. The sample dye contaminated water showed degradation of around $95 \%$ for all the dyes. Hence, through this study, we can confirm that B.megaterium can be used for the treatment of dye contaminated soils and water. Though decolorization is obtained through efficient studies, there is still the need for further studies to understand the degradation mechanism of azo compounds under natural conditions by B.megaterium.

\section{References}

[1] Robinson, T.; McMullan, G.; Marchant, R. \& Nigam, P. (2001). Remediation of dyes in textile effluent: a critical review on current treatment technologies with a proposed alternative. Bioresource Technology, 77:247-255

[2] Stolz A (2001). Base and applied aspects in the microbial degradation ofazodyes. Appl. Microbiol. Biotechnol. 56:69-80

[3] Khalid.A.,Arshad.M., and Crowley.D.E., 2008. Decolorization of azo dyes by Shewanella sp. Under saline conditions. Appl. Microbiol. Biotechnol.79:1053- 1059.

[4] L.K. Wang, Y.T. Hung, N.K. Shammas (Eds.), Physicochemical Treatment Processes, vol. 3 Humana Press, New Jersey (2004), pp. $141-198$

[5] Jyotsna Kiran Peter and PriyamVandana, (2014) Congo red dye decolourization by partially purified laccases from Pseudomonas aeruginosa,International Journal of current microbiology and applied sciences, 3:105-115.

[6] Weisburger JH. Comments on the history and importance of aromatic and heterocyclic amines in public health. Muta Res. 2002; 506-507:9-20.

[7] Sewgil SaaduldeenAnwer and SawanMerkhan (2013), Removal of Different Dyes by Pseudomonas fluorescens, Journal of Life Sciences, 7:51-56.

[8] Selvam, K., Swaminathan, K., and Chae, K.S. (2003) Decolourization of azo dyes and a dye industry effluent by a white rot fungus Thelephora sp. Bioresour. Technol. 88, 115-119

[9] Lowry, O.H., Rosebrough, N.J., Farr, A.L., Randall, R.J., 1951. Protein measurement with the Folin phenol reagent. The Journal of Biological Chemistry 193, $265 \mathrm{e} 275$.

[10] Saratale RG, Saratale GD, Chang JS, Govindwar SP (2009) Ecofriendly degradation of sulfonated diazo dye C.I. Reactive Green 19A using Micrococcus glutamicus NCIM-2168. Bioresour Technol 100: 3897-3905.

[11] Hedge, J.E. and Hofreiter, B.T. (1962). In: Carbohydrate Chemistry17 (Eds. Whistler R.L. and Be Miller, J.N.), Academic Press, New York.

[12] R.C. Senan, T.E. Abraham, "Bioremediation of textile azo dyes by aerobic bacterial, consortium," Biodegradation, Vol. 15, pp.275$280,2004$.

[13] Harshad S. Lade a, Tatoba R. Waghmode a, Avinash A. Kadam b, Sanjay P. Govindwar a, * International Biodeterioration \& Biodegradation 72 (2012) 94e107.

[14] Maulin P Shah, Biodegradation of Azo Dyes by Three Isolated Bacterial Strains: An Environmental Bioremedial Approach., Shah, J Microbial Biochem Technol 2014, S3.

[15] Susan R. Macwana, Sumit Punj, John Cooper, Evan Schwenk and Gilbert H. John., Identification and Isolation of an Azoreductase from Enterococcus faecium, Curr. Issues Mol. Biol. 12: 43-4

\section{Theses:}

[16] Pandu krishnaCompalaprabhakar (2013) Bioremediation of textile dyes and improvement of plant growth by marine bacteria: Thesis report,University of Boras,No.11.

Lekha K .Nair r. "Biodegradation of Azo Dyes Using Bacillus Megaterium and Its Phytotoxicity Study." IOSR Journal of Environmental Science, Toxicology and Food Technology (IOSRJESTFT) 11.7 (2017): 12-20. 